\title{
Knowledge, Attitude, and Practices of Mothers towards Children Immunization during COVID-19 Pandemic
}

\author{
Amira Mohamed Saad Mohammed Khali1 ${ }^{1,3}$, Asmaa Ghareeb Mohamed ${ }^{2,3}$ \\ ${ }^{1}$ Assistant Professor of Pediatric Nursing, Faculty of Nursing, Tanta University \\ ${ }^{2}$ Assistant Professor of Community Health Nursing, Faculty of Nursing, Assiut University. \\ ${ }^{3}$ Nursing Department, College of Applied Medical science, Hafr Al Batin University
}

\begin{abstract}
\end{abstract}
Background: Parental knowledge, practice, and attitudes towards vaccination are important factors in predicting a child's immunization status especially during COVID quarantine. Aim of the study: This study was conducted to assess mothers' knowledge, attitude, and practice regarding children immunization during COVID Pandemic at Hafr- Al-Batin City. Subjects and method: Descriptive analytical cross-sectional was performed from 30 June 2020 until 25 July 2020. 126 Mothers who had at least one child at the immunization period were included in the study using convenience and snowball sampling methods. An online questionnaire was used by the researchers to obtain the necessary data. This questionnaire consisted of four parts was designed to gather the participants' data. Part 1; Sociodemographic characteristics, Part 2; Mothers' knowledge about childhood immunizations during COVID 19, Part 3; Mothers' practices about children's immunizations, and Part 4; Mothers Attitude toward infants' immunizations during COVID 19 pandemic. Result: slightly less than half $(46 \%)$ of the mothers has a good level of knowledge. Also, the majority $(84.2 \%)$ of the mothers had a satisfactory level of practice. $41.3 \%$ of the mother disagree that vaccination side effects are dangerous, about two-thirds $(65.1 \%)$ of them strongly agree that COVID causes a delay in immunization, and about half of them (50.8) strongly agree on fear from going to child Vaccination during COVID. Conclusion: about half of the mothers have a good level of knowledge and the majority of them had a satisfactory level of practice. Moreover, about two-thirds of them strongly agree that COVID causes a delay in immunization.

Keywords: Knowledge, Attitude, Practices, Mothers, COVID-19, Pandemic, Children Immunization 


\section{Tanta Scientific Nursing Journal}

\section{Introduction:}

WHO recommends that all routine vaccinations be administered as scheduled, even during the COVID-19 pandemic. There is currently no evidence that the COVID-19 pandemic poses any specific risk linked to vaccination. Evidence for other infectious diseases is therefore applied. This evidence suggests that potential contact with an infectious disease is not a contraindication for routine immunization ${ }^{(1,2)}$. Routine immunization sessions should continue to the extent possible and as permitted within the local COVID-19 response context. However, standard infection prevention measures should be in place to minimize the risk of COVID-19 transmission to all staff and visitors to the health facility. Children must receive all the vaccines scheduled at birth and in the first two years of life ${ }^{(3,4)}$. These vaccines may vary according to national recommendations. Any interrupted immunization services for any age groups should be resumed and catch-up vaccinations offered as quickly as possible. Timely vaccination is key to protect young and old from serious and life-threatening infectious diseases, and to avoid the accumulation of unvaccinated groups and potential loss of community immunity ${ }^{(5-7)}$. In the Kingdom of Saudi Arabia The basic vaccinations identified in the Vaccination
Certificate, from birth until the first grade, aim to protect children in the Kingdom and all target groups in the community against diseases targeted by immunization, to maintain the Kingdom polio-free, and to get rid of measles, rubella, and mumps, as well as reducing the infection rates of other diseases targeted by immunization. (8) Within the framework of the keen interest shown by the Ministry of Health $(\mathrm{MOH})$ to achieve these objectives and to remind families or parents of their children vaccination dates to follow them up, the Ministry herein presents the approved version of the National Immunization Schedule, with effect from January 1st, $2013^{(8)}$.

Immunizations are an essential health service that protects susceptible individuals from vaccine-preventable diseases (VPD). By providing timely immunizations, individuals and communities remain protected and the likelihood of a VPD outbreak decreases, Preventing a VPD outbreak not only saves lives but requires fewer resources than responding to the outbreak and helps reduce the burden on a health system already strained by the COVID-19 pandemic ${ }^{(6)}$. According to the global immunization division CDC report, the global parental Attitude and knowledge regarding immunization services were low and parents have negative beliefs about 
measles and vaccination programs ${ }^{(9,10)}$. Thus, Parental attitudes and beliefs about vaccines are an important factor in predicting a child's immunization status, especially during COVID quarantine. This study shall provide vital data on mothers' knowledge, attitude, and practice regarding infants' immunization during COVID quarantine at Hafr- Al-Batin City of the eastern province of Saudi Arabia.

\section{Aim of the study:}

This study was conducted to assess mothers' knowledge, attitude, and practice regarding children immunization during COVID Pandemic at Hafr- Al-Batin City.

\section{Subjects \& Methods:}

Research Design: Descriptive analytical cross-sectional was performed from 30 June 2020 until 25 July 2020. The study was conducted at, Hafr- Al-Batin city.

Subjects: 126 Mothers who had at least one child at the immunization period were included in the study using convenience and snowball sampling methods.

The tool of the study: an online questionnaire was used by the researchers to obtain the necessary data. A semistructured questionnaire consisted of four parts was designed to gather the participants' data. Part 1: Sociodemographic characteristics such as age, marital status, educational level, economic status, mothers' occupation, Means of transportation, and Time taken to health centers. Part 2: Mothers' knowledge about infants' immunizations during COVID 19. This part including 10 questions with a scoring system as follows; Correct and complete answer was scored (2), Correct and incomplete answer was scored (1), and don't know or incomplete answer was scored (0). Total scores for mothers' knowledge were 20. It was calculated and classified as follows: $\downarrow 60 \%$ were considered poor knowledge, from 60- $\downarrow$ $75 \%$ were considered fair knowledge, and $75-100 \%$ were considered good knowledge. Part 3: Mothers' practices about infants' immunizations during COVID 19. This part including 11 questions. Three levels of scoring for each question were used: Correct and complete answer was scored (2), Correct and incomplete answer was scored (1), and don't know or incomplete answer was scored (0). Total scores for mothers' knowledge were 22. Total scores of mothers' practice were calculated and classified as follows: $\downarrow 60 \%$ were considered unsatisfactory practice and $>60$ were considered a satisfactory practice

Part 4: Mother's Attitude toward infants' immunizations during COVID 19 pandemic. The mother's attitude is measured using a 5 Likert scale ranging from strongly agree to strongly disagree. 


\section{Tanta Scientific Nursing Journal}

\section{Method:}

Official approval from the dean of the college of applied medical science was obtained to conduct the study. The actual complete participation via an online questionnaire was considered as an approval to participate in the study. The questionnaire was translated into the Arabic language by the researcher. The questionnaire is disseminated through students' accounts on social media (Facebook, WhatsApp, and so on) who directly disseminate it to their mothers, sisters, and relatives. At the start of the questionnaire, the purpose of the study and the confidentiality of data is stated. Then the researcher stated that when they complete the questionnaire and make submit, this considers an agreement to participate in the study. A pilot study was done before embarking in the field of work on $10 \%$ of total subjects to ascertain the clarity and applicability of the study tools. The pilot subjects were excluded from the study sample.

\section{Anticipated ethical issues}

Informed consent from participants was assured when they completing the online questionnaire and submit it. The right of the participant to withdraw at any time or continue in the study was protected. The research purpose was clarified to the participants before answering the questions. The participant was not at risk during the study. The anonymity of participants was protected and confidentiality was assured.

Statistical analysis: The data were coded, entered, revised, tabulated, and analyzed using SPSS (version 20). Descriptive statistics (frequency numbers and Percentages), mean and standard deviation were calculated. Paired t-tests were used to analyze the relationships; statistical significance was set at a P-value $<0.05 \%$.

\section{Results}

Table 1 represents the characteristics of the studied children and their mothers. It was found that nearly two-thirds of the studied children $(67.4 \%)$ were males. Concerning their age, it was clear that about two-thirds of them (66.2\%) above 12 months and the rest below 12 months. The finding revealed that the vast majority of children (93.7\%) hadn't any chronic disease. The table also revealed that the age of nearly three quarters $(77 \%)$ of the mothers was between $20-<30$. Slightly more than two-thirds of them $(66.2 \%)$ were in university education and more than three-quarters of them were employed. Slightly more than half of them reported low income.

Table 2 illustrate the immunization details of children. Slightly less than twothirds of the mother $(60.3 \%)$ stated that 


\section{Tanta Scientific Nursing Journal}

their source of knowledge about vaccination is health professionals. Most of them $(95.2 \%)$ had child immunization cards and $95.1 \%$ of them mentioned that they vaccinated the child in a Governmental health center. Moreover, slightly more than two thirds $(69.8 \%)$ of children were immunized totally.

Table 3 explains total knowledge and practice among studied mothers. It was obvious that slightly less than half $(46 \%)$ of the mothers had a good level of knowledge and about one-third of them (36.5\%) had a fair level. Also, the majority $(84.2 \%)$ of the mothers had a satisfactory level of practice.

Table 4 represents mothers' attitudes toward infants' immunizations during COVID Quarantine. The table explained that more than two thirds $(69.8 \%)$ of the mothers strongly agreed on the favorable opinion regarding immunization, nearly about three quarter $(73.0 \%)$ of them strongly agreed that immunization is important, and slightly less than two thirds $(60.3 \%)$ of them strongly agreed that vaccination is safe. Furthermore, about two-thirds $(65.1 \%)$ of them strongly agreed that immunization maintains child health, about one-third $(30.2 \%)$ of them strongly agreed that immunization prevents disease transmission, and about one-third of them disagreed that immunization harms child health. Also, $41.3 \%$ of the mother disagreed that vaccination side effects are dangerous, while $73.0 \%$ of them disagreed that immunization gives immunity against COVID, about two thirds $(65.1 \%)$ of them strongly agreed that COVID causes a delay in immunization, and about half of them (50.8\%) strongly agreed on fear from going to child Vaccination during COVID. Moreover, $65.1 \%$ of the mothers strongly agreed that child wears a face shield when going to immunization, $73.0 \%$ of them disagreed that vaccination increase a child's risk of becoming infected with COVID-19 or of developing the disease, $31.7 \%$ of them disagreed that COVID-19 a contraindication for vaccination, and $41.3 \%$ of them were uncertain that the BCG vaccine protects against COVID-19.

Table (5) illustrates the most common causes of vaccination delay. More than half of mothers $(55.6 \%)$ stated that the most common causes of vaccination delay were child sickness. $19.0 \%$ of them related common causes of vaccination delay to forgotten immunization time.

Table 6 illustrates the relation between mothers' socioeconomic characteristics and total knowledge and practice. The highest score of knowledge was in the age $>40$ whereas the highest score of practice was in the age between $30-<40$. Regarding mothers' educational level, the 
highest mean of knowledge and practice was in the postgraduate group. Additiontionally, the highest score of knowledge and practice was in the moderate level of income with a mean of $15.36 \pm 2.6$ and $16.81 \pm 3.2$ respectively. Concerning marital status, the highest mean of knowledge and practice was in the widow mothers group with a mean of 17.0 \pm .00 and $19.0 \pm .00$ respectively. While the employed mothers have the highest score of knowledge and practice with a mean of $14.28 \pm 2.1$ and $17.35 \pm 2.9$ respectively. There was a statistically significant correlation between mothers' socioeconomic characteristics and total knowledge and practice. Moreover, the highest score of knowledge was found to be among moderate-income levels whereas the highest score of practice was found at the low-income level. Also, the table illustrates that the employed mother has a high score of knowledge, while the unemployed mother has a high score of practice. 
Table 1: Socio-demographic characteristics of the study participant.

\begin{tabular}{|c|c|c|}
\hline \multirow{2}{*}{$\begin{array}{l}\text { Socio-demographic characteristics } \\
\text { of the studied children and their } \\
\text { mothers }\end{array}$} & \multicolumn{2}{|c|}{$\begin{array}{c}\text { Study Participant } \\
(\mathrm{n}=126)\end{array}$} \\
\hline & No & $\%$ \\
\hline \multicolumn{3}{|l|}{ characteristics of the studied children } \\
\hline $\begin{array}{l}\text { Sex: } \\
\text { Males } \\
\text { Females }\end{array}$ & $\begin{array}{l}85 \\
41\end{array}$ & $\begin{array}{l}67.4 \\
32.6\end{array}$ \\
\hline 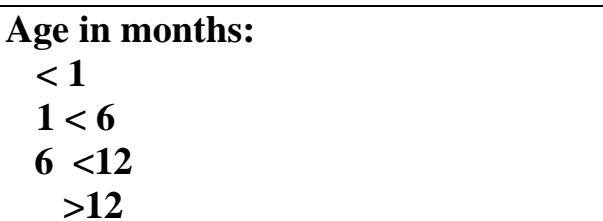 & $\begin{array}{c}8 \\
6 \\
16 \\
96\end{array}$ & $\begin{array}{l}6.3 \\
4.8 \\
12.7 \\
66.2\end{array}$ \\
\hline Mean \pm SD & \multicolumn{2}{|c|}{$4.95 \pm 1.61$} \\
\hline $\begin{array}{l}\text { Presence of chronic disease } \\
-\quad \text { Yes } \\
-\quad \text { No } \\
\end{array}$ & $\begin{array}{c}8 \\
118\end{array}$ & $\begin{array}{c}6.3 \\
93.7\end{array}$ \\
\hline \multicolumn{3}{|l|}{ Mothers characteristics } \\
\hline $\begin{array}{l}\text { Age (years) } \\
20<30 \\
30<40 \\
\quad>40 \\
\end{array}$ & $\begin{array}{l}77 \\
35 \\
14\end{array}$ & $\begin{array}{l}61.1 \\
27.8 \\
11.1\end{array}$ \\
\hline $\begin{array}{l}\text { Educational level: } \\
\text { - Illiterate } \\
\text { - Moderate } \\
\text { - High } \\
\text { - University } \\
\text { - Postgraduate } \\
\end{array}$ & $\begin{array}{c}12 \\
8 \\
16 \\
86 \\
4 \\
\end{array}$ & $\begin{array}{c}9.5 \\
6.3 \\
12.7 \\
68.3 \\
3.2 \\
\end{array}$ \\
\hline $\begin{array}{l}\text { Employment: } \\
\text {-Yes } \\
\text { - No }\end{array}$ & $\begin{array}{l}98 \\
28\end{array}$ & $\begin{array}{l}77.8 \\
22.2\end{array}$ \\
\hline $\begin{array}{ll}\text { Marital status } \\
-\quad \text { Married } \\
-\quad \text { Widow } \\
\end{array}$ & $\begin{array}{c}124 \\
2\end{array}$ & $\begin{array}{c}98.4 \\
1.6\end{array}$ \\
\hline \begin{tabular}{ll}
\multicolumn{2}{l}{ Income level } \\
$-\quad$ Low \\
$-\quad$ Moderate \\
$-\quad$ High \\
\end{tabular} & $\begin{array}{l}66 \\
22 \\
38\end{array}$ & $\begin{array}{l}52.4 \\
17.5 \\
30.2\end{array}$ \\
\hline
\end{tabular}


Table (2): Immunization details of children

\begin{tabular}{|c|c|c|}
\hline \multirow[t]{2}{*}{ Immunization details of children } & \multicolumn{2}{|c|}{$\begin{array}{l}\text { Studied children } \\
\qquad(\mathrm{n}=126)\end{array}$} \\
\hline & No & $\%$ \\
\hline $\begin{array}{l}\text { Source of knowledge about } \\
\text { vaccination: } \\
\text { Health professionals } \\
\text { Neighbors } \\
\text { Relatives } \\
\text { TV } \\
\text { Internet } \\
\end{array}$ & $\begin{array}{c}67 \\
2 \\
14 \\
2 \\
32 \\
\end{array}$ & $\begin{array}{c}60.3 \\
1.6 \\
11.1 \\
1.6 \\
25.4\end{array}$ \\
\hline $\begin{array}{l}\text { Presence of immunization card: } \\
\text { Yes } \\
\text { No }\end{array}$ & $\begin{array}{c}120 \\
6 \\
\end{array}$ & $\begin{array}{c}95.2 \\
4.8 \\
\end{array}$ \\
\hline $\begin{array}{l}\text { Place of immunization: } \\
-\quad \text { Governmental } \\
-\quad \text { Private }\end{array}$ & $\begin{array}{c}116 \\
10\end{array}$ & $\begin{array}{c}92.1 \\
7.9\end{array}$ \\
\hline $\begin{array}{ll}\text { Child status of immunization: } \\
-\quad \text { Total } \\
-\quad \text { Partial } \\
\end{array}$ & $\begin{array}{l}88 \\
38 \\
\end{array}$ & $\begin{array}{l}69.8 \\
30.2\end{array}$ \\
\hline
\end{tabular}

Table 3: Total knowledge and Practice of Studied Mothers

\begin{tabular}{|c|c|c|}
\hline \multirow[t]{2}{*}{ Total knowledge and Practice } & \multicolumn{2}{|c|}{$\begin{array}{l}\text { Studied mothers } \\
\qquad(n=126)\end{array}$} \\
\hline & No. & $\%$ \\
\hline \multicolumn{3}{|l|}{ Levels of total knowledge: } \\
\hline Good & 58 & 46.0 \\
\hline Fair & 46 & 36.5 \\
\hline Poor & 22 & 17.5 \\
\hline \multicolumn{3}{|l|}{ Total knowledge scores: } \\
\hline Range & \multicolumn{2}{|c|}{$11-19$} \\
\hline Mean $\pm S D$ & \multicolumn{2}{|c|}{$14.25 \pm 2.56$} \\
\hline \multicolumn{3}{|l|}{ Levels of total practice: } \\
\hline Unsatisfactory practice & 20 & 15.8 \\
\hline Satisfactory practice & 106 & 84.2 \\
\hline \multicolumn{3}{|l|}{ Total practice scores: } \\
\hline Range & \multicolumn{2}{|c|}{$11-21$} \\
\hline Mean $\pm S D$ & \multicolumn{2}{|c|}{$16.96 \pm 2.867$} \\
\hline
\end{tabular}


Table 4: Mother's Attitude toward Children Immunizations during COVID Pandemic.

\begin{tabular}{|c|c|c|c|c|c|}
\hline \multirow{3}{*}{$\begin{array}{c}\text { Mothers Attitude toward infants' } \\
\text { immunizations }\end{array}$} & \multicolumn{5}{|c|}{ Studied mothers $(\mathrm{n}=126)$} \\
\hline & $\begin{array}{l}\text { Strongly } \\
\text { Agree }\end{array}$ & Agree & Uncertain & Disagree & $\begin{array}{l}\text { Strongly } \\
\text { disagree }\end{array}$ \\
\hline & No $(\%)$ & No $(\%)$ & No $(\%)$ & No $(\%)$ & No $(\%)$ \\
\hline Favorable opinion on immunization & $88(69.8)$ & $36(28.6)$ & $2(1.6)$ & - & - \\
\hline Immunization is important & $92(73.0)$ & $34(27.0)$ & - & - & - \\
\hline Vaccination is safe & $76(60.3)$ & $42(33.3)$ & $8(6.3)$ & - & - \\
\hline Immunization maintain child health & $82(65.1)$ & $24(19.0)$ & $20(15.9)$ & - & \\
\hline Immunization prevent disease transmission & $38(30.2)$ & $36(28.6)$ & $40(31.7)$ & $6(4.8)$ & - \\
\hline Immunization harms child health & $2(1.6)$ & $2(1.6)$ & $52(41.3)$ & $40(31.7)$ & $30(23.8)$ \\
\hline $\begin{array}{l}\text { Immunization gives immunity against } \\
\text { COVID }\end{array}$ & $16(12.7)$ & $92(73.0)$ & $18(14.3)$ & - & - \\
\hline COVID 19 causes a delay in Immunization & $82(65.1)$ & $24(19.0)$ & $10(7.9)$ & $8(6.3)$ & $2(1.6)$ \\
\hline Vaccination side effects are dangerous & $4(3.2)$ & $4(3.2)$ & $48(38.1)$ & $52(41.3)$ & $18(14.3)$ \\
\hline $\begin{array}{l}\text { Fear from going to child Vaccination } \\
\text { during COVID } 19\end{array}$ & $64(50.8)$ & $50(39.7)$ & - & $4(3.2)$ & $8(6.3)$ \\
\hline $\begin{array}{l}\text { The child wears a face shield when going } \\
\text { to Immunization }\end{array}$ & $82(65.1)$ & 24(19.0) & $10(7.9)$ & $8(6.3)$ & $2(1.6)$ \\
\hline $\begin{array}{l}\text { vaccination increase a child's risk of } \\
\text { becoming infected with COVID-19 or of } \\
\text { developing the disease }\end{array}$ & $16(12.7)$ & $92(73.0)$ & $18(14.3)$ & - & - \\
\hline $\begin{array}{llll}\text { COVID-19 } & \text { a } & \text { contraindication } & \text { for } \\
\text { vaccination } & & & \end{array}$ & $2(1.6)$ & $2(1.6)$ & $52(41.3)$ & $40(31.7)$ & $30(23.8)$ \\
\hline
\end{tabular}

Table 5: Causes of Vaccination Delay other than COVID-19

\begin{tabular}{|l|c|c|}
\hline \multirow{2}{*}{ Causes of vaccination delay } & \multicolumn{2}{|c|}{ Studied mothers (n=126) } \\
\cline { 2 - 3 } & No & \% \\
\hline Forgotten immunization time & 24 & 19.0 \\
Child sickness & 70 & 55.6 \\
Social cause & 12 & 9.5 \\
Absence of vaccination & 18 & 14.3 \\
Mother sickness & 2 & 1.6 \\
Total & 126 & 100.0 \\
\hline
\end{tabular}


Table 6: Relation between Mothers' Socioeconomic Characteristics and Total Knowledge and Practice.

\begin{tabular}{|c|c|c|c|}
\hline $\begin{array}{l}\text { Socioeconomic } \\
\text { characteristics }\end{array}$ & $\begin{array}{c}\text { Total } \\
\text { knowledge }\end{array}$ & Total practice & \multirow[t]{2}{*}{$\begin{array}{c}\text { T } \\
\text { p-value }\end{array}$} \\
\hline Mother age & \multicolumn{2}{|c|}{ Mean \pm Std. Deviation } & \\
\hline$-\quad 20>30$ & $14.27 \pm 2.59$ & $16.87 \pm 2.97$ & \multirow{3}{*}{$\begin{array}{c}24.405 \\
.000 *\end{array}$} \\
\hline$-\quad 30<40$ & $13.88 \pm 2.37$ & $17.42 \pm 2.64$ & \\
\hline$-\quad>40$ & $15.07 \pm 2.81$ & $16.35 \pm 2.79$ & \\
\hline \multicolumn{4}{|l|}{ Educational level } \\
\hline - Illiterate & $14.0 \pm .000$ & $16.0 \pm .000$ & \multirow{5}{*}{$\begin{array}{r}5.508 \\
.000 *\end{array}$} \\
\hline - $\quad$ Moderate & $13.50 \pm 2.44$ & $14.75 \pm 2.65$ & \\
\hline - $\quad$ High school & $14.75 \pm 3.33$ & $17.12 \pm 1.40$ & \\
\hline - $\quad$ University & $14.18 \pm 2.54$ & $17.34 \pm 3.07$ & \\
\hline - $\quad$ Post graduate & $16.0 \pm .000$ & $18.5 \pm 2.88$ & \\
\hline \multicolumn{4}{|l|}{ Income level } \\
\hline - Low & $13.81 \pm 2.6$ & $17.60 \pm 2.7$ & \multirow{3}{*}{$\begin{array}{l}22.563 \\
.000 *\end{array}$} \\
\hline - Moderate & $15.36 \pm 2.6$ & $16.81 \pm 3.2$ & \\
\hline - High & $14.36 \pm 2.1$ & $15.94 \pm 2.6$ & \\
\hline \multicolumn{4}{|l|}{ Marital status } \\
\hline - $\quad$ Married & $14.20 \pm 2.5$ & $16.93 \pm 2.8$ & \multirow{2}{*}{$\begin{array}{r}46.147 \\
.000 *\end{array}$} \\
\hline - Widow & $17.0 \pm .000$ & $19.0 \pm .000$ & \\
\hline \multicolumn{4}{|l|}{ Employment } \\
\hline - Yes & $14.28 \pm 2.1$ & $17.35 \pm 2.9$ & 32.869 \\
\hline - $\quad$ No & $14.24 \pm 2.6$ & $16.8 \pm 2.8$ & 32.869 \\
\hline
\end{tabular}

*Correlation is significant at the 0.05 level. 


\section{Tanta Scientific Nursing Journal}

\section{Discussion}

Household isolation and COVID-19 illness

in families with new-born children, combined with disruption to vaccine supply, healthcare staffing shortages, and enhanced infection prevention procedures, are likely to significantly reduce opportunities for timely delivery of routine immunizations ${ }^{(11,12)}$. Parental knowledge, practice, and attitudes towards vaccination are an important factor in predicting a child's immunization status, especially during COVID quarantine. Our research revealed that the majority of mothers' knowledge was good and fair. Besides, the practice of the majority of them was satisfactory. From the researchers' point of view, this result may be related to the efforts of the Ministry of Health in the Kingdom of Saudi Arabia in awareness of the community about the importance of childhood vaccination during the COVID pandemic. Also, there is a significant correlation between mothers' education and their knowledge and practice where the majority of the mothers who A higher university education have a high score of knowledge and practice. A higher educational level, of no doubt, helps the parents to understand the educational messages. Moreover, such parents have better chances to come across considerable knowledge about immunization in the media. This results in agreement with Yousif et al. $(\mathbf{2 0 1 3})^{(13)}$, they found a significant association between parents' educational level and knowledge and attitudes on childhood immunization.

The main source of information regarding immunization among totally immunized children was found to be health personnel. This was similar to the findings of a study conducted by M.M. Angadi (2013) (14). From the researchers' point of view, this is since vaccination information is usually given for mothers by health professionaljust before infants/ children taking vaccines with each immunization sessions or at the time of antenatal checkups. Vaccination uptake among the study subject was high and the majority of children have immunization cards. However, this study has shown that the majority of mothers vaccinated their children in a governmental health center. This result may be explained in the light of the mother conception that if a vaccine is promoted by the government and recommended by consultant pediatricians, the vaccine was perceived to be important and necessary. In the present study, it was found that immunization status was not significantly associated with other factors such as maternal education, children's sex, and socioeconomic status. This result in line with M.M. Angadi (2013) ${ }^{(14)}$. From 


\section{Tanta Scientific Nursing Journal}

the researchers point of view this result may be attributed to the continuous encouragement and enforcement of the Ministry of Health in the Kingdom of Saudi Arabia to all mothers to continue children during the COVID pandemic. Also, the Ministry of Health reminding parents of the vital need to protect their children against serious vaccinepreventable diseases, even as the COVID19 pandemic continues.

The majority of mothers had expressed positive attitudes towards immunization. In general, the idea of vaccines, particularly against life-threatening infections was perceived positively whereas the majority of them agreed that immunization is important, safe, and maintain child health. Similar findings were reported by $\mathbf{E}$ Bystrom et al. (2017) ${ }^{(15)}$. This result may be related to the continuous awareness from the medical and nursing staff at all children and maternity health centers about the advantages and importance of childhood vaccination. Also, the majority of mothers disagree that vaccination increase a child's risk of becoming infected with COVID-19 or of developing the disease, and also they disagreed that COVID-19 was a contraindication for vaccination. On the other hand, the majority of them have a negative attitude towards immunization during the COVID-
19 pandemic whereas the majority of the mothers had feared going to child vaccination during the COVID-19 pandemic, and this lead to delay in immunization as mothers stated. The mothers' negative attitude towards immunization during the COVID-19 pandemic may be explained in well-child of parental concerns about potentially exposing their children to COVID-19 during well child visits. Furthermore, the mothers explaining that the most common cause of vaccination delay other than COVID-19 was child sickness. childhood researcher point of view, this may be related to parent communication with health staff in cases of children sickness and they know that vaccination is contraindicated during children illness. Moreover, most of the mothers agreed that the child should wear a face shield when going to immunization. Mothers following to universal precaution is to protect their children from COVID-19 and this in agreement with the recommendation of the Ministry of Health in the Kingdom of Saudi Arabia for immunization during the COVID-19 pandemic (16). Also WHO illustrated that parents can be informed that although it is important to provide timely vaccinations, their mothers need to follow guidance by national and local governments on COVID-19 preventive 
measures ${ }^{(6)}$ The mothers' good knowledge is reflected in their attitude as the majority of the mothers disagreed that BCG vaccine protect against COVID-19 and also the majority of them disagree that immunization gives immunity against COVID-19. This may be related to the high level of mothers' education and their continuous reading about COVID 19 as it is a novel infectious disease. Also, social media play important role in increasing mother awareness about COVID 19 pandemic.

\section{Conclusions:}

The total level of knowledge of slightly less than half of the mothers was good and about one-third of them were fair. Also, the majority of the mothers had a satisfactory level of practice. Almost twothirds of the mothers strongly agree that COVID causes a delay in immunization, and about half of them strongly agree on fear from going to child Vaccination during COVID.

\section{Recommendation}

1. Ministry of Health in the Kingdom of Saudi Arabia should continue to increase parent awareness about childhood immunization.

2. Health care providers should emphasize and assure the parent about the importance of continuing children vaccination during the COVID 19 pandemic.

3. Health care providers should emphasize to the parent about the importance of following the universal precaution in children's vaccination during the COVID 19 pandemic.

\section{References:}

1- Guidance on routine immunization services during the COVID-19 pandemic in the WHO European Region. Copenhagen: WHO Regional Office for Europe; 2020. Available at http://www.euro.who.int/en/healthtopics/communicablediseases/hepatitis/publications/2020/g uidance-on-routine-immunizationservices-during-covid-19-pandemicin-the-who-european-region-2020, accessed 10 June 2020).

2- The draft landscape of COVID-19 candidate vaccines. Geneva: WHO; 2020. Available at https://www.who.int/who-documentsdetail/draft-landscape-of-covid-19candidate-vaccines accessed 10 June 2020).

3- Guiding principles for immunization activities during the COVID-19 pandemic, 2020. https://apps.who.int/ iris/bitstream/handle/10665/331590/W $\underline{\mathrm{HO}-2019-\mathrm{nCoV}-}$ 
immunization_services-2020.1-

eng.pdf

4- COVID-19: Strategic Planning and Operational Guidance for Maintaining Essential Health Services during an Outbreak, $20 \quad$ March 2020. https://www.who.int/publications-

detail/covid-19-operational-guidance-

for-maintaining-essential-health-

services-during-an-outbreak

5- WHO. Table 3: Recommendations* for Interrupted or Delayed Routine Immunization - Summary of WHO Position Papers, Available at https://www.who.int/immunization/pol icy/Immunization_routine_table3.pdf

6- World Health Organization and the United Nations Children's Fund (UNICEF), Immunization in the context of COVID-19 pandemic,2020.

7- Vaccine safety and false contraindications for vaccination. Training manual. Copenhagen: WHO Regional Office for Europe; 2017 (http://www.euro.who.int/ data/assets/pdf_file/0009/351927/WH O-Vaccine-Manual.pdf accessed 10 June 2020).

8- The Kingdom of Saudi Arabia Ministry of Health (MOH), National Immunization Schedule 2013.

9- Takahashi S, Metcalf CJ, Ferrari MJ, Moss WJ, Truelove SA, Tatem AJ, et al. Reduced vaccination and the risk of measles and other childhood infections post-Ebola. Science J, 2015; 347(6227):1240-2.

10- Rubin LG, Levin MJ, Ljungman P, Davies G, Avery R, Tomblyn M et al. 2013 IDSA clinical practice guideline for vaccination of the immunocompromised host. Clin Infect Dis. 2014;58(3):309-18.

11- Kirsten S. Attitudes and Beliefs of Parents Concerned about Vaccines: Impact of Timing of Immunization Information.Pediatrics;2011:127,S120.

12- Ann Chen Wu. Postpartum Mothers' Attitudes, Knowledge, and Trust Regarding Vaccination. Published in final edited form as Maternal Child Health J2008;12(6): 766-773.

13-Yousif MA, Ahmed Abdulrahman Albarraq, Mustafa Awad A Abdallah, and Abubaker Ibrahim Elbur. Parents' Knowledge and Attitudes on Childhood Immunization, Taif, Saudi Arabia. J Vaccines Vaccin,2013; 5(1): $1-5$.

14- M.M. Angadi, Arun Pulikkottil Jose, Rekha Udgiri, K.A. Masali, and Vijaya Sorganvi. A Study of Knowledge, Attitude, and Practices on Immunization of Children in Urban Slums of Bijapur City, Karnataka, 
India. J Clin Diagn Res. 2013 Dec;

7(12): 2803-2806.

15-E Bystro “m, A Lindstrand, A Roth. Attitudes towards vaccinations in the National Immunization Program among parents in Sweden 2016. European Journal of Public Health, 2017; 27 (3):150-155.

16- Instruction for children immunization during COVID pandemic. The Kingdom of Saudi Arabia Ministry of Health (MOH), 3 April 2020. 